\title{
Supporting Information \\ Polymers with hemiaminal ether linkages for pH-responsive antibacterial materials
}

\author{
Piangtawan Phoungtawee, ${ }^{a}$ Farzad Seidi, ${ }^{a}$ Alongkot Treetong, ${ }^{b}$ Choochart Warin, ${ }^{b}$ Annop Klamchuen, ${ }^{b}$ and Daniel Crespya,* \\ a Department of Materials Science and Engineering, School of Molecular Science and Engineering, Vidyasirimedhi Institute \\ of Science and Technology (VISTEC), Rayong 21210, Thailand \\ b National Nanotechnology Center (NANOTEC), National Science and Technology Development Agency (NSTDA), 111 \\ Thailand Science Park, Phahonyothin Road, Khlong Nueng, Khlong Luang, Pathum Thani 12120, Thailand \\ *E-mail: $\underline{\text { daniel.crespy@vistec.ac.th }}$
}

\section{Experimental section}

\section{Materials}

4-(vinyloxy)butyl methacrylate (VBMA) was synthesized following a reported method. ${ }^{1}$ 6-chloropurine (> 98\%, TCI Chemicals), trifluoroacetic acid (TFA, 99\%, Acros Organics), ethyl acetate anhydrous (99.9\%, Acros Organics), triethylamine ( $\geq 99 \%$, Merck), hexane (95\%, Carlo Erba), ethyl acetate (99.5\%, Honeywell), silicone modified aliphatic urethane acrylate (EBECRYL ${ }^{\circledR 8890,70 \% ~ r e s i n ~ c o n t e n t, ~ A l l n e x), ~ 2,2-d i m e t h o x y-2-p h e n y l a c e t o p h e n o n e ~(I r g a c u r e ~ 621, ~>~}$ 98\%, TCI chemicals), hydrochloric acid ( $\mathrm{HCl},>36.5 \%$, Carlo Erba), dimethyl sulfoxide-d 6 (99.9\%,Cambridge Isotope Laboratories), deuterium oxide ( $\mathrm{D}_{2} \mathrm{O}, 99.9 \%$, Merck) and chloroform-D (99.8\%,Cambridge Isotope Laboratories) were used without further purification. SCDLP broth was prepared by mixing $30 \mathrm{~g}$ of Tryptic Soy Broth (Bacto, USA), $1 \mathrm{~g}$ of L- $\alpha$ Phosphatidylcholine from soybean,Type II-S (14-29\% choline basis, Sigma-Aldrich) and 7 g of Tween 80 (Merck) with 1 L of water. Then, the pH of solution was adjusted to 7.2. Deionized water was used throughout this work.

\section{Synthesis of 4-(1-(6-chloro-7H-purin-7-yl) ethoxy) butyl methacrylate (CPBMA)}

CPBMA was synthesized according to the literature method with a little modification. ${ }^{2}$ VBMA (9.536 g, $\left.51.7 \mathrm{mmol}, 1 \mathrm{eq}\right)$ and 6-chloropurine ( $4 \mathrm{~g}, 25.9 \mathrm{mmol}, 0.5 \mathrm{eq}$ ) were dissolved in $10 \mathrm{~mL}$ anhydrous ethyl acetate in a $50 \mathrm{~mL}$ round bottom flask. Then, $0.25 \mathrm{~mL}$ of TFA was added to the reaction mixture and the reaction was stirred at $25{ }^{\circ} \mathrm{C}$ for $7 \mathrm{~h}$ under nitrogen atmosphere. The solvent was removed with a rotary evaporator. Before purification, dimers were observed, as possible products of the cationic polymerization of CPBMA. The product was purified by column chromatography on silica gel and washed firstly with a solution containing $100 \mathrm{~mL}$ hexane and $1 \mathrm{~mL}$ triethylamine followed by washing with a mixture of hexane:ethyl acetate (4:1 v:v) to provide $6.24 \mathrm{~g}$ (71\% yield) as yellowish viscous solution. ${ }^{1} \mathrm{H}$ NMR spectroscopy (600 MHz, $\left.\mathrm{CDCl}_{3}\right): \delta 8.77(\mathrm{~s}, 1 \mathrm{H}), 8.34(\mathrm{~s}, 1 \mathrm{H}), 6.07(\mathrm{~s}, 1 \mathrm{H}), 6.03(\mathrm{q}, 1 \mathrm{H}, J=6 \mathrm{~Hz}), 5.55(\mathrm{~s}, 1 \mathrm{H}), 4.1(\mathrm{~m}, 2 \mathrm{H}), 3.56(\mathrm{~m}, 1 \mathrm{H}), 3.32(\mathrm{~m}, 1 \mathrm{H})$, 1.94(s, 3H), 1.83(d, 3H, $J=6 \mathrm{~Hz}), 1.75-1.63(\mathrm{~m}, 4 \mathrm{H}) .{ }^{13} \mathrm{C}$ NMR spectroscopy $\left(600 \mathrm{MHz}, \mathrm{CDCl}_{3}\right): \delta 167.5,152.3,151.7,151.4$, 142.6, 136.4, 131.9, 125.7, 81.9, 69.1, 64.6, 25.8, 25.3, 22.4, 18.4. Calcd for $\mathrm{C}_{15} \mathrm{H}_{19} \mathrm{ClN}_{4} \mathrm{O}_{3} 338.1146[\mathrm{M}+\mathrm{H}]^{+}$, found 338.1190 .

\section{Preparation of $\mathrm{P}(\mathrm{UA}-\mathrm{co}$-CPBMA) coatings}

Cold-rolled steel plates (CRS: SPCC, composition wt\%: 99.295\% Fe, 0.5\% Mn, 0.12\%C, $0.04 \%$ P, and 0.045\% S) with dimension of $2.0 \times 2.0 \times 0.1 \mathrm{~cm}$ were used as metallic substrates. The plates were polished with 400 grit SiC abrasive papers 
using a metallographic grinding and polishing machine (Jinan Kason Testing Equipment Co., Ltd.), washed with deionized water, ethanol, and then dried in vacuum desiccator. The coating solution was prepared by mixing $3 \mathrm{~g}$ of EBECRYL ${ }^{\circledR 8890,}$ $150 \mathrm{mg}$ of CPBMA and $42 \mathrm{mg}$ of Irgacure $621 \mathrm{in} 10 \mathrm{~mL}$ amber vial stirring at $300 \mathrm{rpm}, 28{ }^{\circ} \mathrm{C}$ for $30 \mathrm{~min}$. Then, $0.2 \mathrm{~mL}$ of mixed solution was spin-coated on steel plates at $500 \mathrm{rpm}$ for $30 \mathrm{~s}$ with a ramping acceleration of $250 \mathrm{rpm} / \mathrm{s}$ and then at $4500 \mathrm{rpm}$ for $40 \mathrm{~s}$ with an acceleration of $2250 \mathrm{rpm} / \mathrm{s}$. Finally, the coated samples were cured with a UV-LED lamp (UV intensity $=34 \mathrm{~mW} / \mathrm{cm}^{2}$ ) for $3 \mathrm{~min}$ with a maximum wavelength of $365 \mathrm{~nm}$. The distance between lamp and the coated sample was 5 cm. FT-IR spectroscopy: 3405 (w, NH), 2920-2859 (m, CH2 ,CH3), 1721 (vs, CO), 1090 (vs, SiO), and 796 cm-1 (vs, $\mathrm{SiC}$ ).

\section{Release of 6-chloropurine from the coated samples}

Glass substrates with a dimension of $2.0 \times 2.0 \times 0.1 \mathrm{~cm}$ were used as substrates for studying release experiment. PUA, P(UACo-CPBMA) and the UV-curable coatings mixed with 6-chloropurine on glass slide were prepared with the aforementioned procedure. Release profiles of 6-chloropurine from the coated samples were determined by placing the coated sample in $3.0 \times 3.0 \times 1.5 \mathrm{~cm}$ plastic boxes followed by addition of $5 \mathrm{~mL}$ of $0.05 \mathrm{M}$ phosphate buffer solutions at pH 7.4 or 3.5. Then, the coated samples were placed in a shaking incubator (N-BIOTEK-205, 32.8 $\left.{ }^{\circ} \mathrm{C}, 100 \mathrm{rpm}\right)$. At given time intervals $(1 \mathrm{~h}, 2 \mathrm{~h}$, 3 h, 4 h, 5 h, 6 h, 1 day, 4 days, 10 days, 20 days, 21 days, 23 days, 27 days, 31 days, 38 days, 48 days and 58 days), $5 \mathrm{~mL}$ of the released media was removed to determine the concentration of released 6 -chloropurine, and replaced by $5 \mathrm{~mL}$ fresh buffer solution. The concentration of 6-chloropurine in the released media was determined by UV-visible spectroscopy. Calibration curves were plotted by measuring a series of 6 -chloropurine solutions with known concentrations at pH values of 7.4, 3.5 and 1.0. (Figure S1b-d).

\section{Hydrolysis of CPBMA monomer}

$5 \mathrm{mg}$ CPBMA was either dissolved in a mixture of $10 \mu \mathrm{L} \mathrm{D}_{2} \mathrm{O}, 2.5 \mu \mathrm{L} \mathrm{HCl}$ solution, and $700 \mu \mathrm{L}$ DMSO-d 6 or a mixture of 10 $\mu \mathrm{L} \mathrm{D}_{2} \mathrm{O}$ and $702.5 \mu \mathrm{L}$ DMSO- $\mathrm{d}_{6}$. The hydrolysis of CPBMA was monitored in triplicate by ${ }^{1} \mathrm{H}$ NMR spectroscopy at different time intervals.

\section{Stability of the PUA coatings in neutral and acidic conditions}

PUA coatings were peeled off and placed in $1 \mathrm{~mL} \mathrm{D} \mathrm{D}_{2} \mathrm{O}$ or a mixture of $900 \mu \mathrm{L} \mathrm{D} \mathrm{D}_{2} \mathrm{O}$ and $100 \mu \mathrm{l}$ of an aqueous solution $1 \mathrm{M} \mathrm{HCl}$. The immersed coatings were placed in a shaking incubator (N-BIOTEK-205, $37^{\circ} \mathrm{C}, 100 \mathrm{rpm}$ ) for 7 days. The solid was separated from the liquid phase by centrifugation (7000 rpm, $30 \mathrm{sec}, 25{ }^{\circ} \mathrm{C}$ ), which was analyzed by ${ }^{1} \mathrm{H}$ NMR spectroscopy. Furthermore, PUA coatings on glass slides were placed in recipients containing $5 \mathrm{~mL}$ of phosphate buffer solutions at pH 7.4 or 3.5 , or in a $0.05 \mathrm{M}$ aqueous solution of $\mathrm{HCl}(\mathrm{pH} \sim 1.3)$. Then, the coated samples were placed in a shaking incubator (N-BIOTEK-205, $37^{\circ} \mathrm{C}, 100 \mathrm{rpm}$ ) for 7 days, and dried at $25{ }^{\circ} \mathrm{C}$. Photographs of the coatings were taken with a high resolution 3.0 megapixels USB microscope (SHODENSHA, Thailand).

\section{Antibacterial activity of the coatings}

$\mathrm{P}(\mathrm{UA}$-co-CPBMA) or P(UA-co-CPBMA) mixed with $15 \mathrm{mg}$ 6-chloropurine were coated on $2.0 \times 2.0 \times 0.2 \mathrm{~cm}$ polyamide substrates (MyPS group Co., Ltd.) and irradiated with a UV light for $15 \mathrm{~min}$ with a maximum wavelength of $254 \mathrm{~nm}$ before testing. $100 \mu \mathrm{l}$ suspension of S. aureus ATCC $6538 \mathrm{P}$ ( 2.5 to $10 \times 10^{5}$ cells $\left./ \mathrm{mL}\right)$ and E. coli ATCC 8739 (2.5 to $10 \times 10^{5}$ cells $\left./ \mathrm{mL}\right)$ were spread onto the coatings or on the polyamide substrate (as control sample). The inocula were covered with polyethylene films and the coatings were incubated for $24 \mathrm{~h}$ at $35{ }^{\circ} \mathrm{C}$ and a relative humidity of $95 \%$. P(UA-Co-CPBMA) coatings were washed with $10 \mathrm{~mL}$ SCDLP broth. Then, $1 \mathrm{~mL}$ of the rinsed bacteria suspension was added to $9.0 \mathrm{~mL}$ normal saline solution $(0.85 \% \mathrm{NaCl}$ in water) and mixed. $1 \mathrm{~mL}$ of the diluted suspension was then mixed with $9.0 \mathrm{~mL}$ normal saline 
solution $(0.85 \% \mathrm{NaCl}$ in water). The process was repeated to provide a serial dilution. $100 \mu$ l of last 3 serially diluted bacteria suspension were spread on TSA medium plate (Difco, USA) then incubated for $24 \mathrm{~h}$ (E. coli) and $48 \mathrm{~h}(S$. aureus) at $35{ }^{\circ} \mathrm{C}$ and a relative humidity of $95 \%$. Finally, the number of bacteria was counted with an automatic colony counter (Scan 1200, Interscience).

\section{Analytical tools}

${ }^{1} \mathrm{H}$ and ${ }^{13} \mathrm{C}$ NMR spectra were recorded on a Bruker $600 \mathrm{MHz}$ NMR spectrometer. Attenuated total reflectance Fourier transform infrared (ATR-FTIR) measurements were performed on a Frontier FTIR spectrometer (PerkinElmer) between 400 to $4000 \mathrm{~cm}^{-1}$ with a resolution of $4 \mathrm{~cm}^{-1}$. Elemental analysis of the coated samples was observed by energy-dispersive X-ray spectroscopy (EDS, X-max $150 \mathrm{~mm}^{2}$ silicon drift detector) coupled with a scanning electron microscope (SEM, ISM7610F, JEOL). X-ray photoelectron spectroscopy (XPS) was performed with a JPS-9010MC apparatus from JEOL with a Mg $\mathrm{K} \alpha$ source $(1253.6 \mathrm{eV})$ at $250 \mathrm{~W}$. All samples were measured under high vacuum pressure in the range of $10^{-8} \mathrm{~Pa}$ at room temperature. Ultraviolet-visible absorption spectra were measured with a UV-vis spectrometer (Cary100, Agilent). Pull-off adhesion tester was done using a PosiTest ${ }^{\circledR}$ pull-off adhesion tester (DeFelsko) according to ASTM D 4541. aluminium Dollies with diameters of $10 \mathrm{~mm}$ diameter were glued on the coating with a two-part epoxy adhesive (ResinLab EP11HT). Samples were then kept at $28{ }^{\circ} \mathrm{C}$ for $24 \mathrm{~h}$ to ensure that the glue fully cured. Then, a testing area was made around dollies and they were pulled vertically at a speed of $4 \mathrm{MPa} / \mathrm{s}$ until the coatings were detached from the metallic substrates. All tests were carried in triplicates. Raman spectra of coatings were recorded with a dispersive Raman microscope (Senterra II, R200-532, Bruker) with a laser excitation wavelength of $523 \mathrm{~nm}$ at $20 \mathrm{~mW}$ and a $20 \times$ microscope magnification. The spectra were collected between 50 and $2700 \mathrm{~cm}^{-1}$ at $25^{\circ} \mathrm{C}$ with a resolution of $3 \mathrm{~cm}^{-1}$. Young's moduli of coatings were obtained by quantitative imaging AFM (NanoWizard Ultra S, JPK Instruments AG) in QI ${ }^{\mathrm{TM}}$ mode at $25{ }^{\circ} \mathrm{C}$. The cantilever-sample distance was defined according to the cantilever stiffness $(200 \mathrm{nN})$ and the z-length $(500 \mu \mathrm{m})$. Mapping resolution and scan size were selected to be $256 \times 256$ pixels and $5 \times 5 \mathrm{~mm}^{2}$, respectively. The Young's Modulus was extrapolated from the slope of the force curve by using Hertz model. The AFM measurements were carried out at three different locations for each coating. Weight loss of coatings was measured by thermal gravimetry analysis (TGA, TGA-DTA8122, Rigaku) from 30 to $700{ }^{\circ} \mathrm{C}$ with a rate of $10^{\circ} \mathrm{C} \mathrm{min}^{-1}$ under a nitrogen atmosphere of $100 \mathrm{SCCM} \cdot \mathrm{min}^{-1}$. The molar mass of CPBMA was determined by LCQuadrupole-Time-of-Flight Tandem Mass Spectrometer (MS, model Compact QTOF, Bruker). 

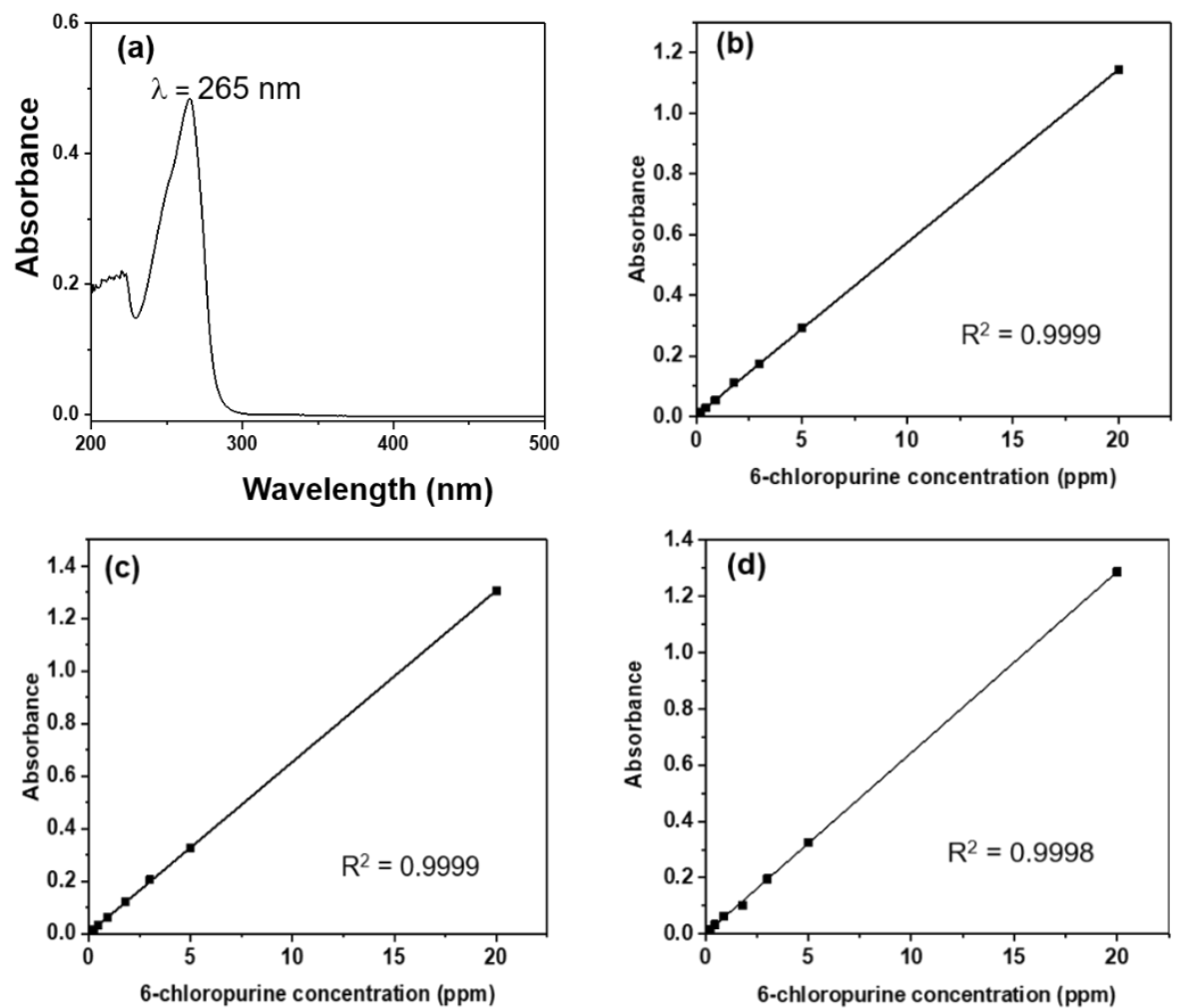

Figure S1. UV-Vis spectrum of (a) CPBMA in $\mathrm{CH}_{2} \mathrm{Cl}_{2}(20 \mathrm{ppm})$. Calibration curves of UV absorbance of 6-chloropurine versus concentration at $\mathrm{pH} 7.4(\mathrm{~b}), 3.5(\mathrm{c})$ and $1.0(\mathrm{~d})$.

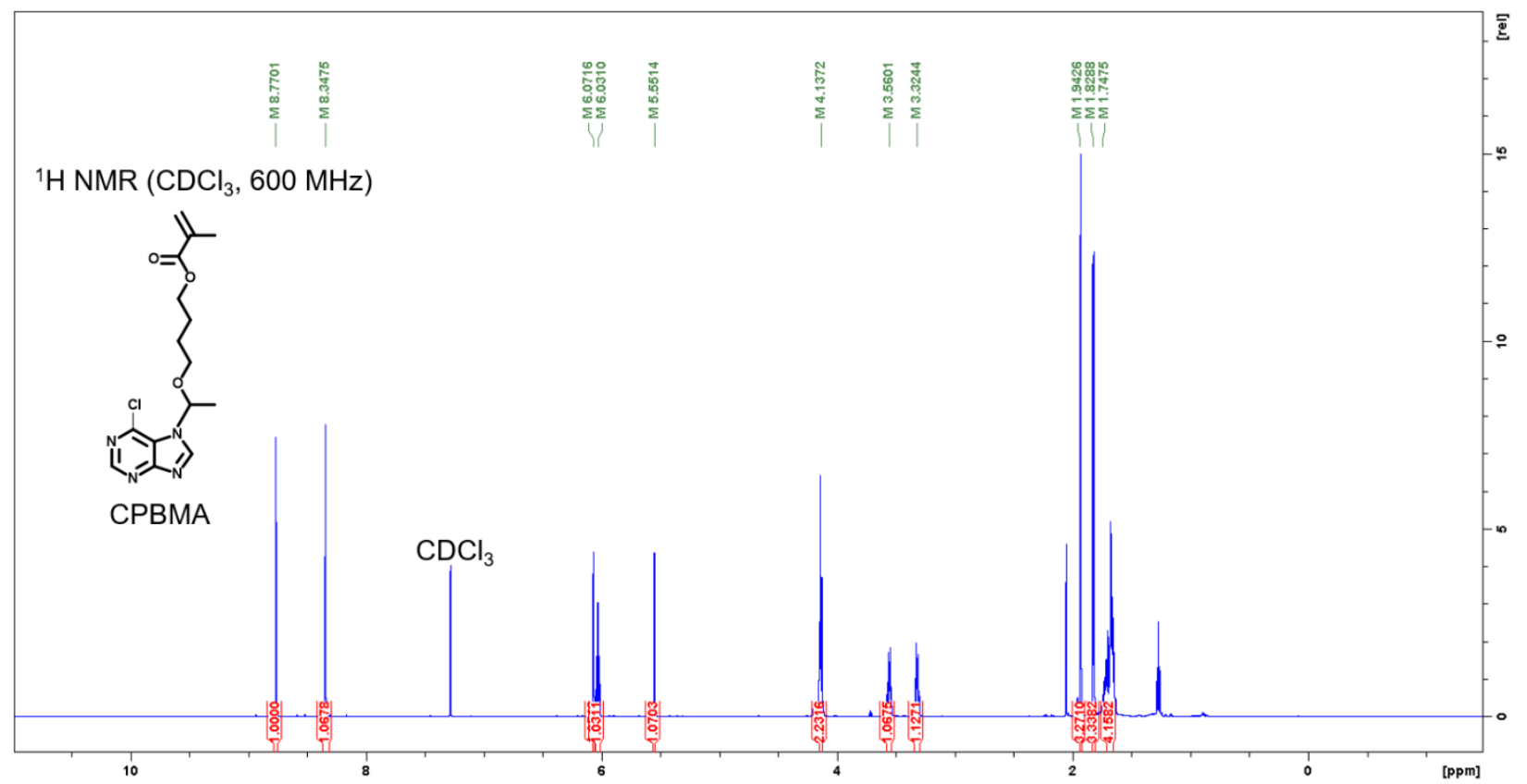

Figure S2. ${ }^{1} \mathrm{H}$ NMR spectrum of CPBMA in $\mathrm{CDCl}_{3}$. 

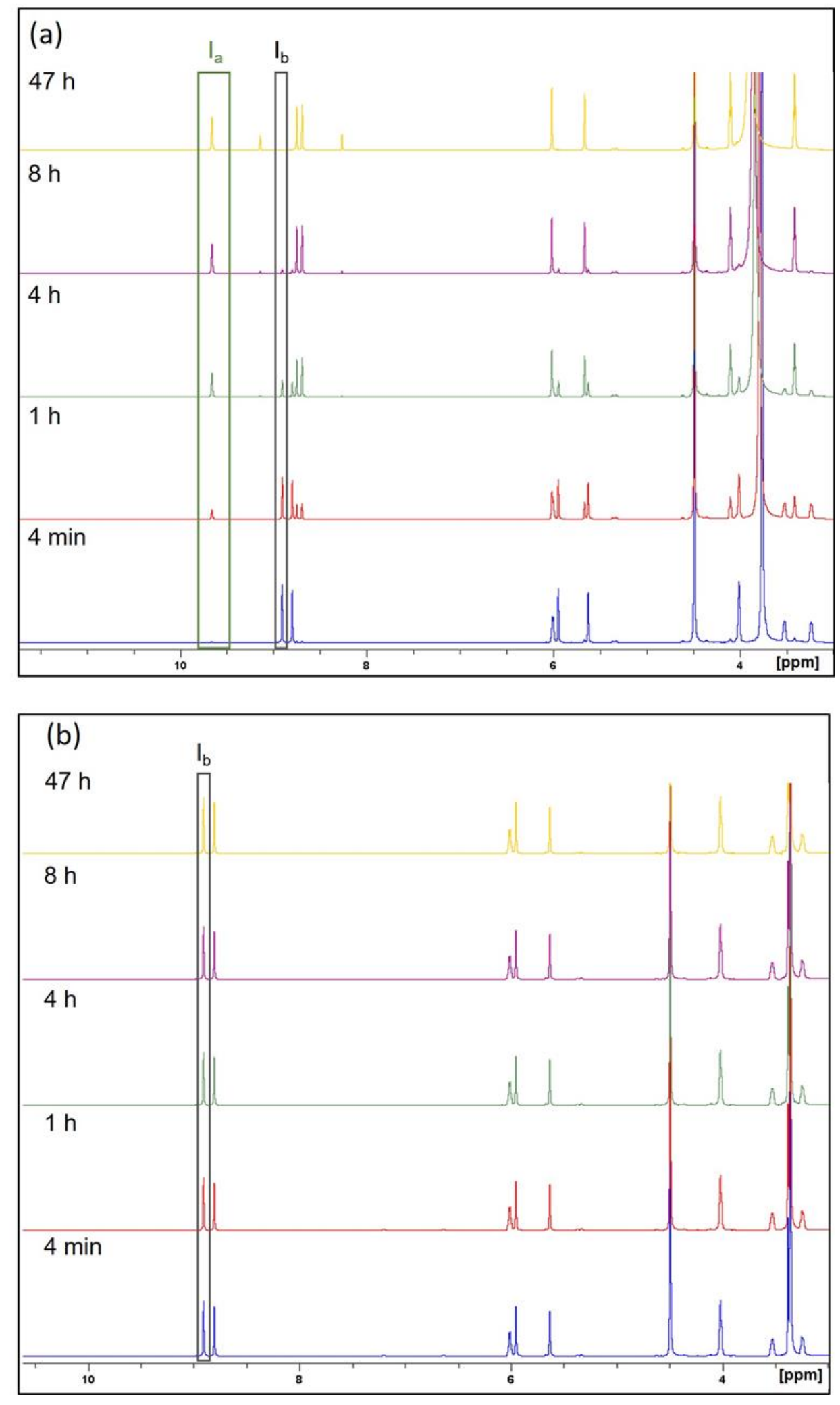

Figure S3. ${ }^{1 \mathrm{H}}$ NMR spectra of CPBMA in DMSO-d6/ $\mathrm{D}_{2} \mathrm{O} / \mathrm{DCl}$ (a) and DMSO-d6/ $\mathrm{D}_{2} \mathrm{O}(\mathrm{b})$. 


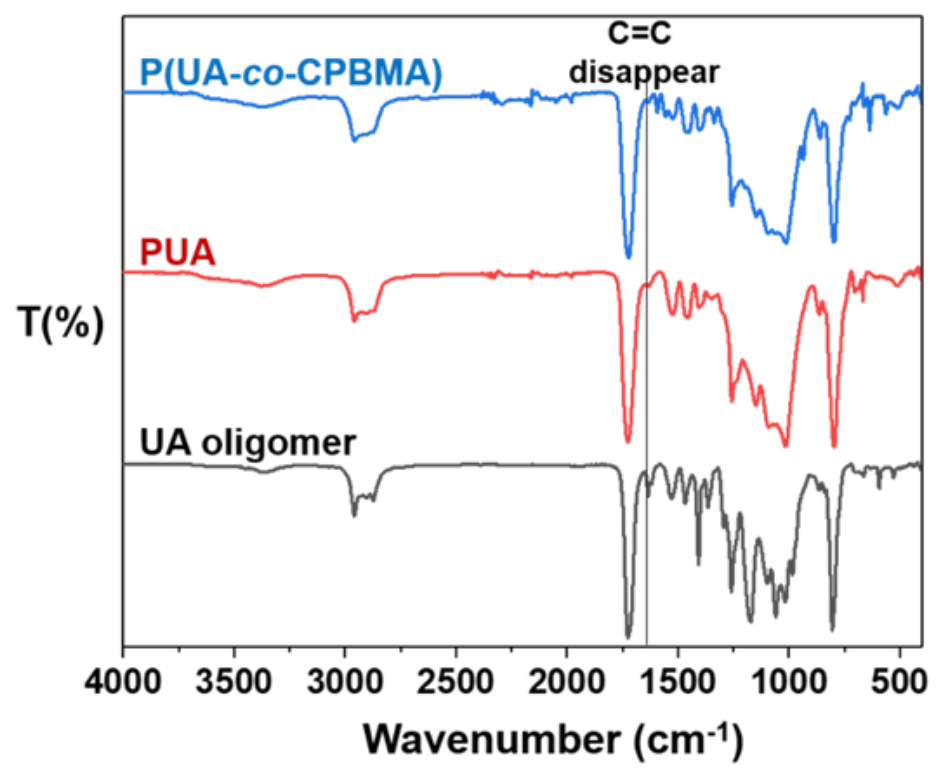

Figure S4. FT-IR spectra of the UA oligomer, PUA coating, and P(UA-co-CPBMA) coating.

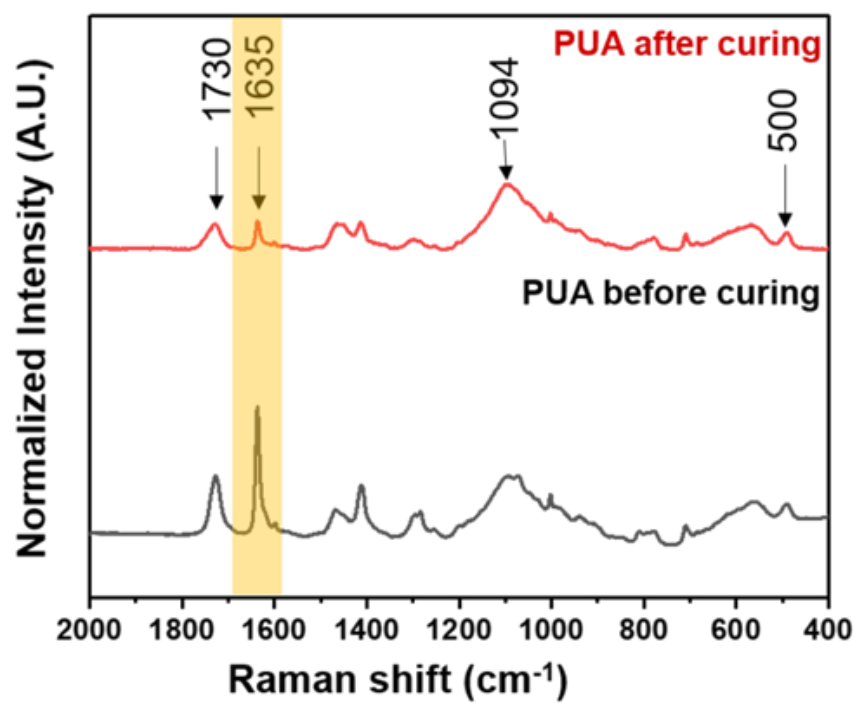

Figure S5. Normalized Raman spectra (relative to the height of the Si-O signal at $500 \mathrm{~cm}^{-1}$ ) of the PUA coatings before and after curing. 


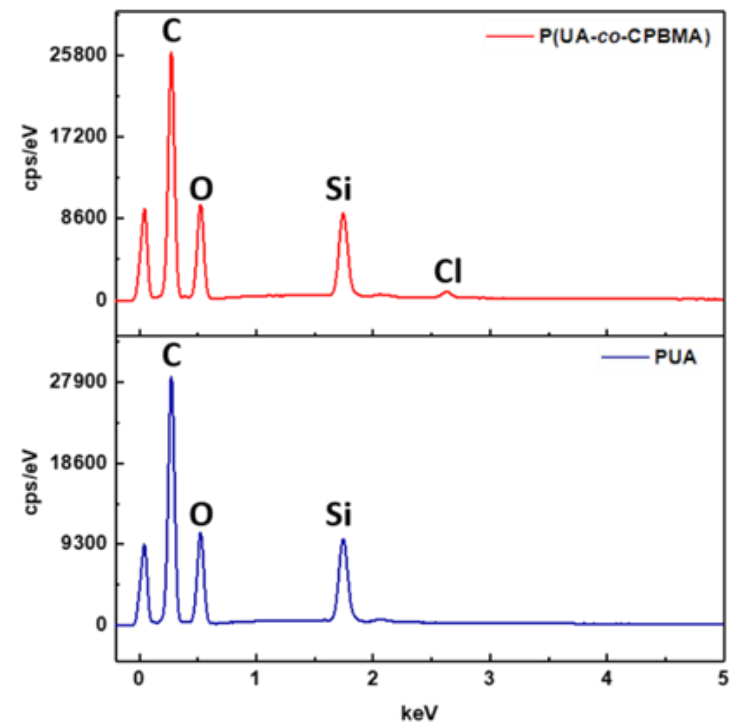

Figure S6. EDS spectra of PUA and P(UA-co-CPBMA) coatings.

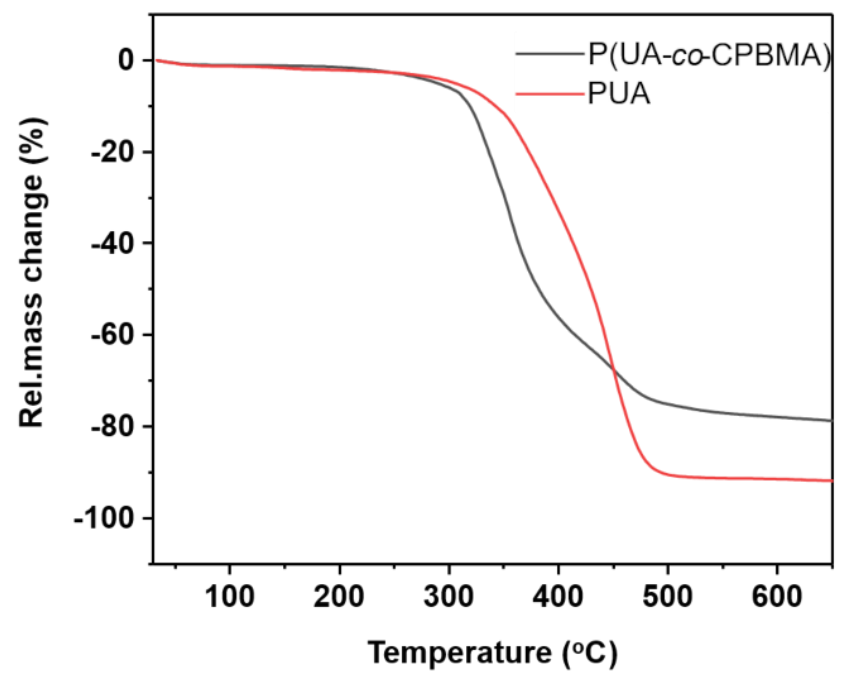

Figure S7. Thermograms of PUA and P(UA-co-CPBMA) coatings. 

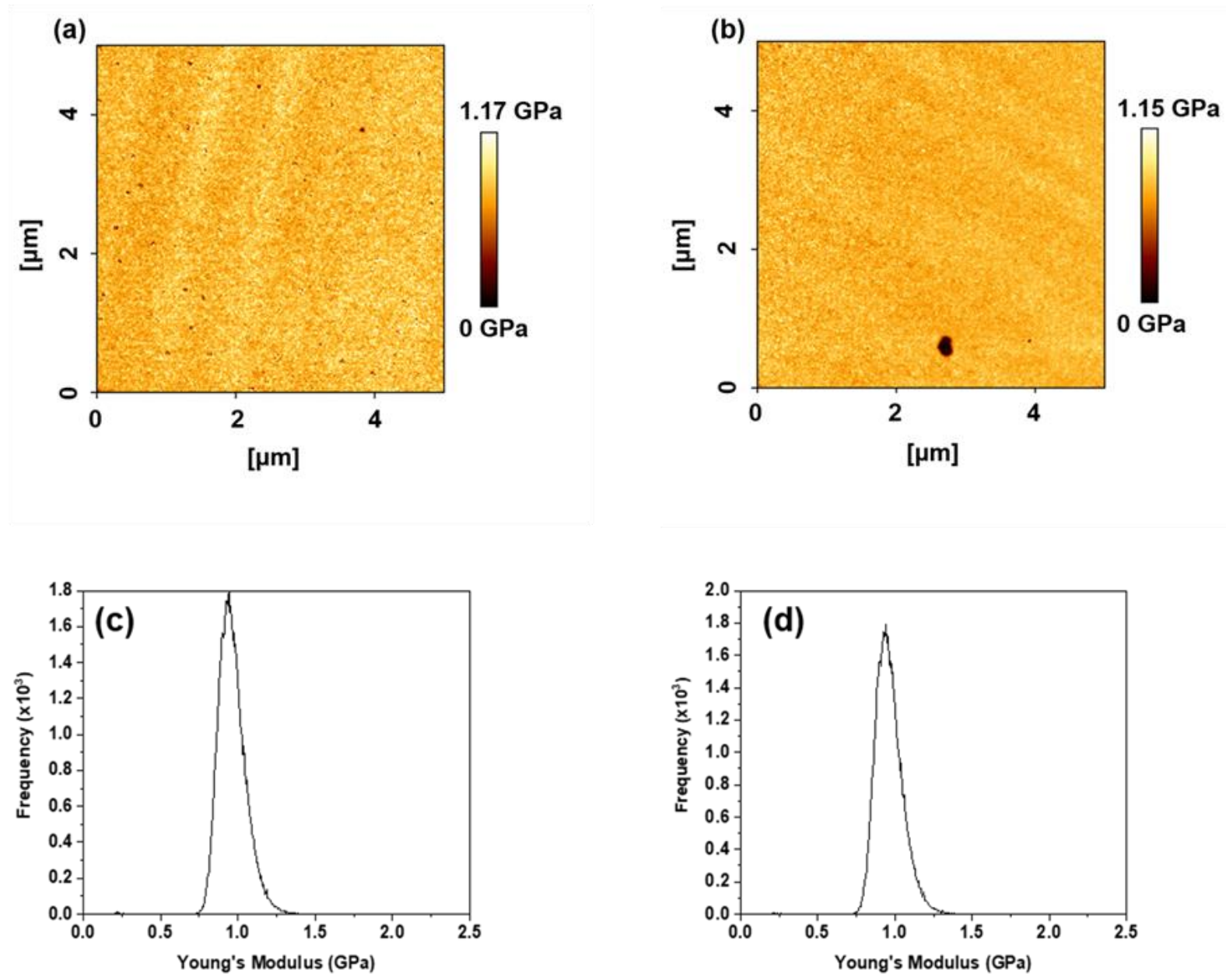

Figure S8. AFM images of the (a) PUA and (b) P(UA-co-CPBMA) coatings. Young s' Modulus histograms of PUA (c) and $\mathrm{P}(\mathrm{UA}-\mathrm{co}$-CPBMA) coatings (d) measured by quantitative imaging AFM.

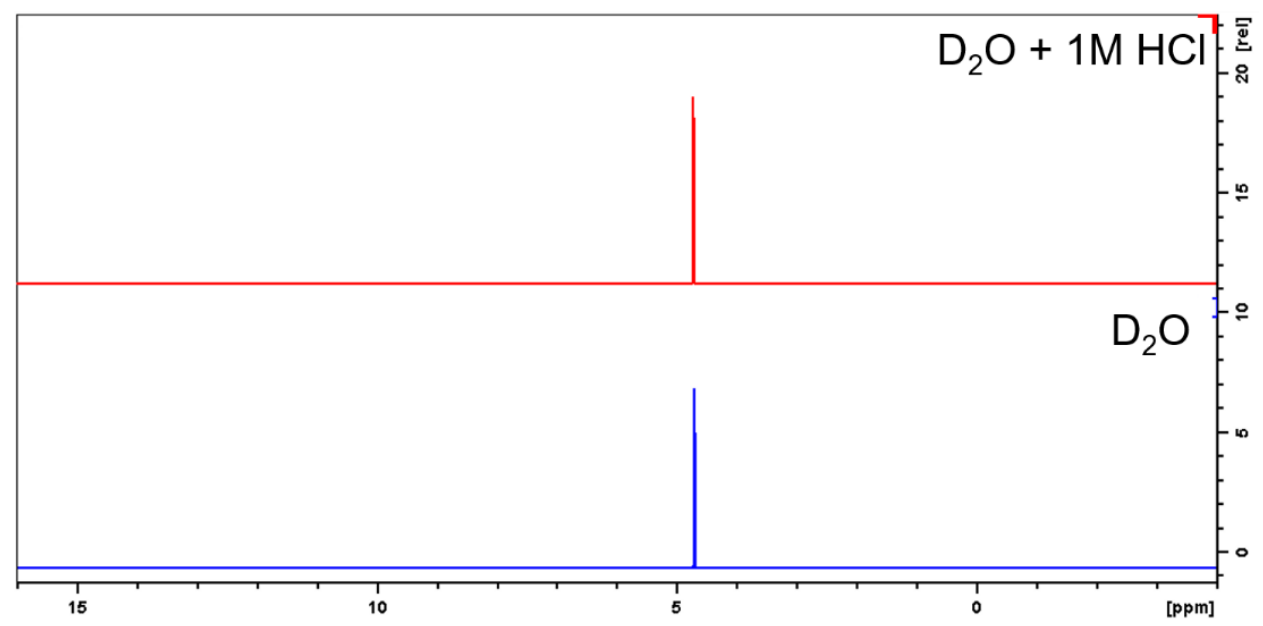

Figure S9. ${ }^{1} \mathrm{H}$ NMR spectra of solutions used for the extraction of PUA coatings for 7 days. 


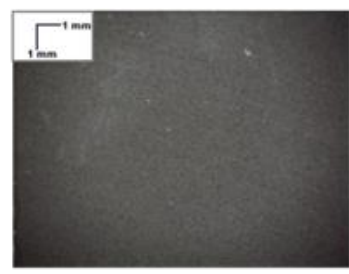

PUA

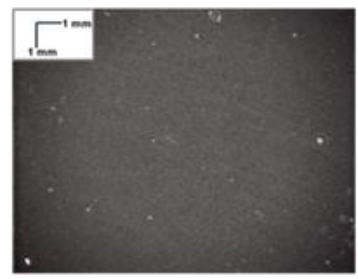

PUA at $\mathrm{pH} 3.5$ for 7 days

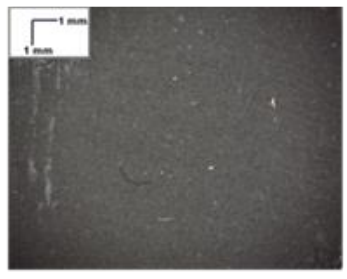

PUA at pH 7.4 for 7 days

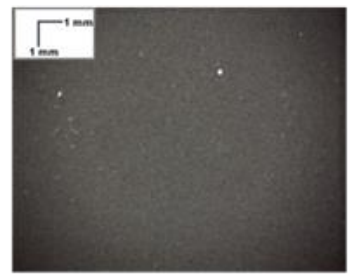

PUA at pH 1.0 for 7 days

Figure S10. Photographs of PUA coatings on glass slides before immersion and after immersion in different buffer solutions (20X magnification).

\section{References}

1 Seidi, F.; Druet, V.; Huynh, N.; Phakkeeree, T.; Crespy, D. Hemiaminal Ether Linkages Provide A Selective Relea se of Payloads from Polymer Conjugates. Chem. Commun. 2018, 54 (97), 13730-13733.

2 Mik, V.; Szüčová, L.; Spíchal, L.; Plíhal, O.; Nisler, J.; Zahajská, L.; Doležal, K.; Strnad, M. N9-Substituted N6-[(3methylbut-2-en-1-yl)amino]purine Derivatives and Their Biological Activity in Selected Cytokinin Bioassays. Bioorg. Med. Chem. 2011, 19 (23), 7244-7251. 